\title{
Aggressive Dorsal Vertebral Hemangioma Causing Compressive Mielopathy
}

\author{
Ana Carla Farias Pimentel ${ }^{*}$, Mariana Santos Leite Pessoa², \\ Francisca Estefânia Mesquita Maciel de Lima ${ }^{3}$, Manuel Joaquim Diógenes Teixeira4, \\ Cláudio Régis Sampaio Silveira ${ }^{5,6}$
}

\footnotetext{
${ }^{1}$ Ana Carla Farias Pimentel, MD, Radiologist, Hospital Geral de Fortaleza (HGF), Fortaleza-CE, Brazil

${ }^{2}$ Mariana Santos Leite Pessoa, MD, Radiology Resident, Hospital Geral de Fortaleza (HGF), Fortaleza-CE, Brazil

${ }^{3}$ Francisca Estefânia Mesquita Maciel de Lima, MD, Pathologist, Laboratório Mikros, Fortaleza-CE, Brazil

${ }^{4}$ Manuel Joaquim Diógenes Teixeira, MD, Orthopedist, Hospital Geral de Fortaleza (HGF), Fortaleza-CE, Brazil

${ }^{5}$ Cláudio Régis Sampaio Silveira, MD, Radiologist, Hospital Geral de Fortaleza (HGF), Fortaleza-CE, Brazil

${ }^{6}$ Hospital São Carlos, Fortaleza-CE, Brazil

Email: ^acarlafp@gmail.com, marianaleite170@gmail.com, esteffmaciel@gmail.com,mjdiogenes@secrel.com.br, claudiosilveira@hotmail.com
}

How to cite this paper: Pimentel, A.C.F. Pessoa, M.S.L., de Lima, F.E.M.M., Teixeira, M.J.D. and Silveira, C.R.S. (2021) Aggressive Dorsal Vertebral Hemangioma Causing Compressive Mielopathy. Open Journal of Medical Imaging, 11, 85-91.

https://doi.org/10.4236/ojmi.2021.113008

Received: June 9, 2021

Accepted: September 27, 2021

Published: September 30, 2021

Copyright (c) 2021 by author(s) and Scientific Research Publishing Inc. This work is licensed under the Creative Commons Attribution International License (CC BY 4.0).

http://creativecommons.org/licenses/by/4.0/

\begin{abstract}
Vertebral hemangiomas are common benign lesions of the spine, characterized by abnormal vascular proliferation, being commonly asymptomatic incidental findings, presenting symptoms in only a small portion of affected individuals. In a smaller number of cases, however, hemangiomas can present an expansive effect and extra-osseous extension, determining a mass effect and neurological symptoms, being therefore called aggressive hemangiomas. On MRI, aggressive hemangiomas are characterized by having a larger vascular component and a smaller fat component, thus producing a low signal on T1-weighted images. We illustrate the case of a young male patient who presented with pain in the upper thoracic spine, who developed paraparesis and ascending sensory deficit and progressive lower limbs, progressing to paraplegia and loss of sphincter control.
\end{abstract}

\section{Keywords}

Aggressive Vertebral Hemangioma, Compressive Myelopathy, Magnetic Resonance Imaging

\section{Introduction}

Vertebral hemangiomas are the most common benign angiomatous lesions involving the spine, with an estimated incidence of $10 \%-12 \%$ based on large au- 
topsy series and reviews of spine radiographs [1]. Histologically, these lesions are composed of fully developed adult blood vessels with slow flowing, dilated venous channels surrounded by fat, infiltrating the medullary cavity [2]. Most vertebral hemangiomas are asymptomatic and incidentally discovered on imaging evaluation of the spine [3].

A rare subset of vertebral hemangiomas, however, is characterized by extraosseous extension, bone expansion, disturbance of blood flow, and occasionally compression fractures and thereby referred to as aggressive hemangiomas [4], and it accounts for approximately $1 \%$ of spinal hemangiomas [5]. Although vertebral hemangiomas are typically incidental findings, they are symptomatic in $0.9 \%$ to $1.2 \%$ of adults [1]. Aggressive vertebral hemangiomas are benign lesions that do not have metastatic potential and are not associated with mortality [6] and may be mistaken for metastasis resulting in unnecessary biopsies, which have a high risk of hemorrhage [7].

In this case report, we aim to describe and illustrate an interesting case of aggressive hemangioma in a young man who coursed with thoracic spine pain and progressive paraparesis, focusing on imaging features.

\section{Case Report}

We report the case of a 28-year-old male patient, who was admitted to the emergency department of a tertiary hospital with a report of sudden, severe pain in the upper dorsal spine, without irradiation or related trauma, which started in November 2018. Two months after the onset of symptoms, he evolved with paraparesis, an ascending and progressive sensory deficit in the lower limbs and, subsequently, with loss of sphincter control and paraplegia.

In this hospitalization, the patient underwent Computed Tomography (CT) of the dorsal spine, which revealed hypodense expansile vertebral mass, with cortical defects and soft tissue extension and spinal cord compression with the "polka dot" sign evidencing thickened vertebral trabeculae. The lesion shows enhancement after iodinated contrast injection (Figure 1). Magnetic Resonance Imaging (MRI) of the dorsal spine showed a large, solid, expansive formation involving the levels from T2 to T4, with invasion of the vertebral canal, determining severe compression and anterior deviation of the vertebral sac and spinal cord, with extension to the T2-T3 and T3-T4 conjugation foramina, infiltrating the pedicles, laminae, transverse processes and T3 spinous process. The lesion exhibits marked hyposignal on T1 weighted images, with some foci of hypersignal, with mild hypersignal on T2, with marked post-contrast enhancement, inferring hypervascularization (Figure 2). There is a restriction on diffusion, with an $\mathrm{ADC}$ measure estimated at $1.9 \times 10^{-3} \mathrm{~mm}^{2} / \mathrm{s}$ (Figure 3 ).

The patient underwent open biopsy of the lesion on August 2020, progressing uneventfully and being discharged a few days later. The biopsy demonstrated bone trabeculae with no particularities with medullary region showing proliferation of a conglomerate of thin-walled blood vessels composed of capillary-sized 


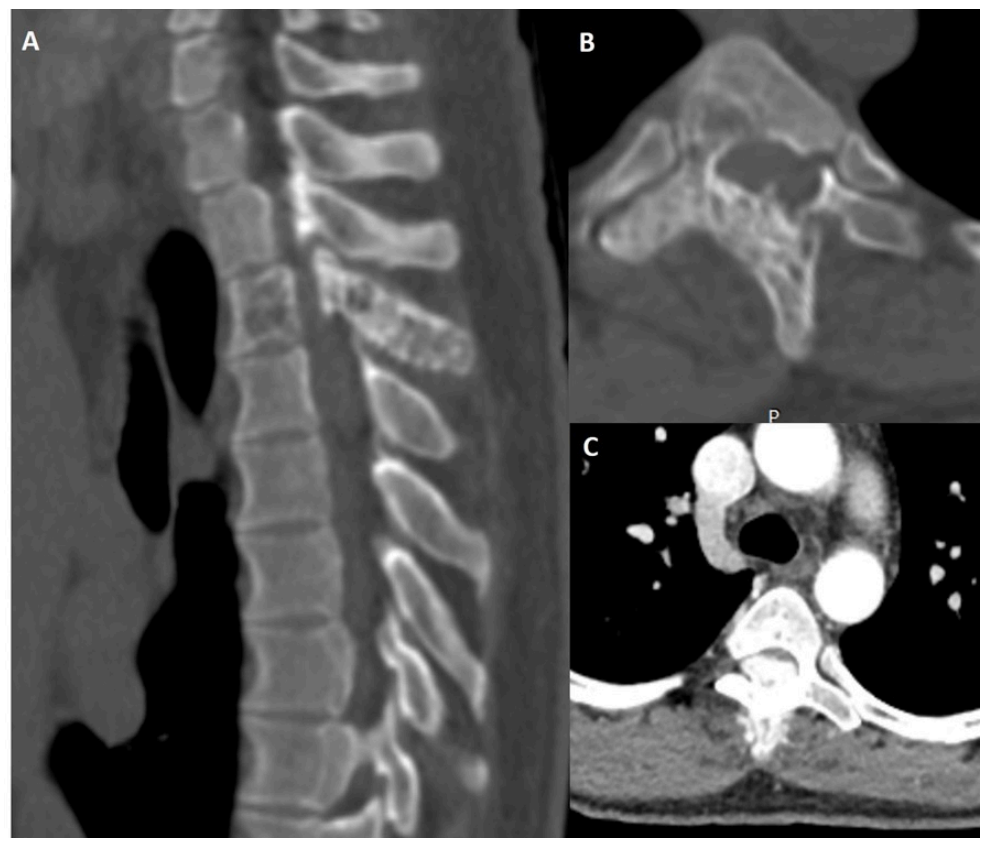

Figure 1. CT images of the dorsal spine in bone window (A) in sagittal section and (B) in axial section show hypodense expansile vertebral mass extending from the levels of T2-T4, with cortical defects and soft tissue extension and spinal cord compression with the "polka dot" sign evidencing thickened vertebral trabeculae in T3 vertebra. (C) CT image in axial section and soft tissue window shows that the lesion has post contrast enhancement.

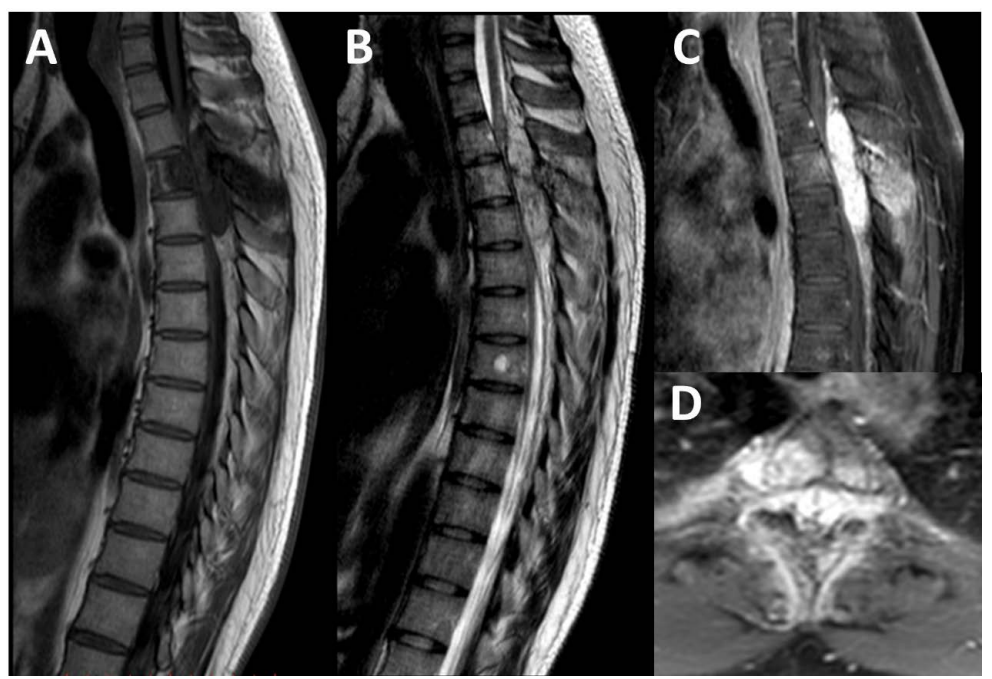

Figure 2. MRI of the dorsal spine show a large, solid, extra-axial, epidural, expansive formation involving the levels from T2 to T4, with epicenter in the vertebral body of T3, with invasion of the vertebral canal, determining severe compression and anterior deviation of the vertebral sac and spinal cord, with extension to the T2-T3 and T3-T4 conjugation foramina, infiltrating the pedicles, laminae, transverse processes and $\mathrm{T} 3$ spinous process. (A) T1-weighted sagittal MRI shows that the lesion exhibits a marked hyposignal, with rare foci of hypersignal in this series. (B) T2-weighted sagittal MRI demonstrates that the lesion exhibits mild hypersignal in this series, with some foci of hyposignal. Post-contrast T1-weighted MRI in (C) sagittal and (D). axial sections demonstrate that the lesion exhibits marked post-contrast enhancement. 


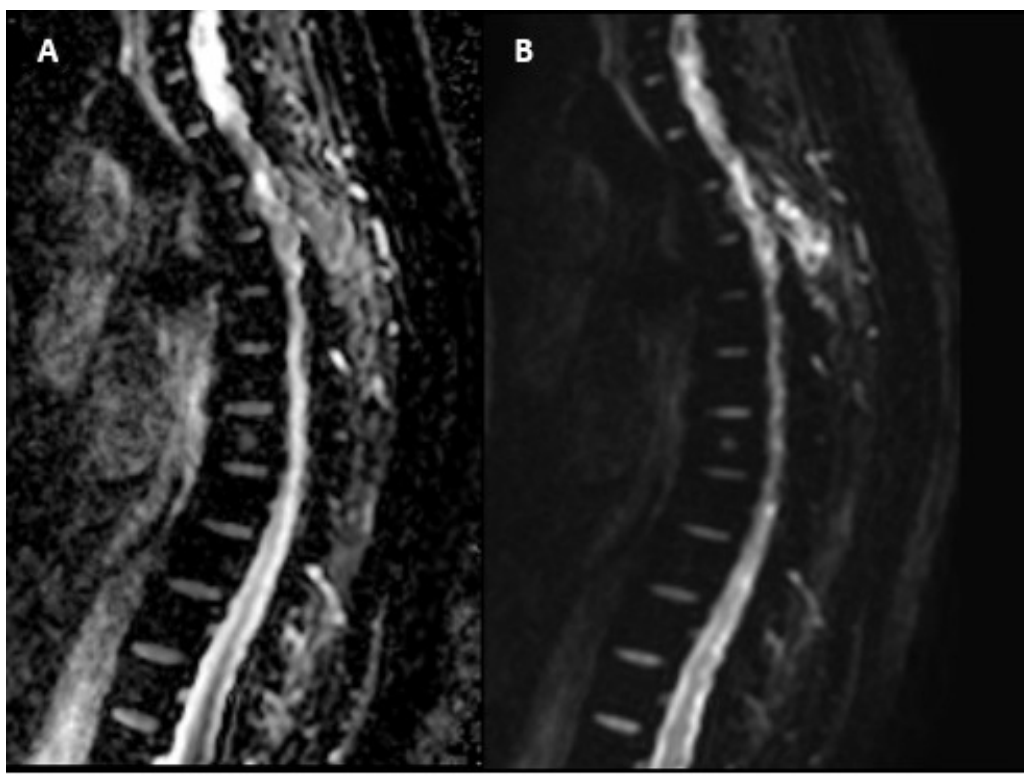

Figure 3. MRI of the dorsal spine in sagittal sections show the lesion presents diffusion restriction, with an ADC measure estimated at $1.9 \times 10^{-3} \mathrm{~mm}^{2} / \mathrm{s}$.

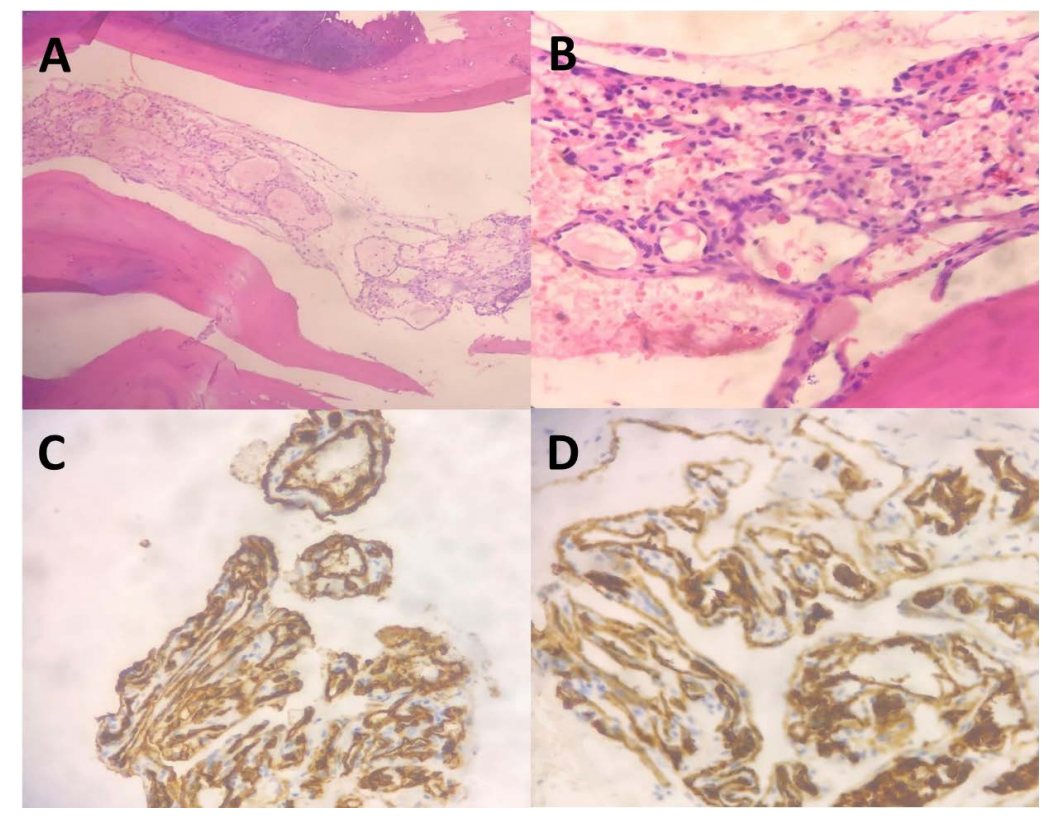

Figure 4. Microscopic findings: (A, B) histological sections stained in hematoxylin-eosin show bone trabeculae with no particularities, with proliferation of small vascular channels lined by typical endothelium. Immunohistochemistry study shows: (C) Anti-CD34 positive in vessels. (D) Anti-CD31 positive in vessels.

vessels some withdilated open channels. The vascular channels are lined by a single layer of flat endothelial cells with no atypia. The vascular channels are complete, are separate, and do not show an anastomosing pattern. The intercellular tissue is composed of loose connective without adipose tissue. Immunohistochemistry study shows anti-CD34 positive and anti-CD31 positive endothelial cells (Figure 4). 


\section{Discussion}

Aggressive hemangiomas can spread not just into the paraspinal soft tissues but also into the epidural region of the spinal canal causing compression and paraparesis [7]. Thus, while uncommon, aggressive hemangioma may present acutely with back pain, radiculopathy or myelopathy, warranting emergent evaluation [5]. These lesions can occur at any age and they have been noted to have a predilection for the thoracic spine, so that $75 \%$ of these lesions occur in the thoracic spine between $\mathrm{T} 3$ and $\mathrm{T} 9$ vertebral segments [8].

The CT findings that suggest an aggressive hemangioma of the spine are hypodense expansile vertebral masses, with cortical defects and soft tissue extension and spinal cord/nerve root compression [9]. Typical "polka-dot" sign in axial images and "corduroy" sign in sagittal images can be helpful in the diagnosis, due to replacement of the normal bone by thickened vertical trabeculae surrounded by fat marrow or vascular lacunae in intraosseous hemangiomas [10]. They generally occupy the entire vertebral body, extend into the neural arch, expand the osseous margins, and contain a soft tissue component [9]. These image aspects could be observed in the case reported, as seen in the images.

In MRI we observe thickened trabeculae appear as low signal areas in both T1 and T2 images [9]. Aggressive hemangiomas typically contain less fat and more vascular stroma thereby producing a low MR signal on T1 weighted images [11]. The extraosseous component typically follows usual hemangioma in all pulse sequences with high $\mathrm{T} 1$ and $\mathrm{T} 2$ signals as well as uniform post-contrast enhancement [9]. Methods of diffusion-weighted MRI with the construction of ADC maps enables visualization of restriction of diffusion of water molecules associated with proliferative activity and high cell density, which is typical for the tumor process, what enables the nature of the lesion to be differentiated [12]. Some studies show that the ADC value of vertebral hemangiomas is significantly higher than that of malignant lesions [12]. A study performed by Geneidi et al demonstrated the diagnostic value of a restricted pattern by DWI for the discrimination between benign and malignant lesions, and the results showed that the best cut-off criterion is ADC of 0.67 , and this means that 0.67 indicates malignant result while $>0.67$ is defined as benign results with a sensitivity of $94 \%$, specificity of $79 \%$ and accuracy of $87 \%$ [13]. According to Neubauer et al., mean ADC $1.03 \times 10^{-3} \mathrm{~mm}^{2} / \mathrm{s}$ is a strong indicator of malignancy at the first diagnosis, with a sensitivity of $90 \%$ and a specificity of $91 \%$ [14]. In the case we reported above, the measure of the ADC value was estimated at $1.9 \times 10^{-3} \mathrm{~mm}^{2} / \mathrm{s}$, suggesting benignity, although it presented aggressive behavior.

The differential diagnosis of aggressive vertebral hemangiomas includes plasmacytoma, metastases and lymphoma [15]. Surgery is required in cases of rapid or progressive neurological symptoms like compressive myelopathy or radiculopathy [15]. Radiation, embolization, vertebroplasty, and ethanol injection have also been used in combination with surgery [15]. Despite the variety of available treatment options, the optimal management strategy is unclear because aggres- 
sive vertebral hemangiomas are uncommon lesions, making it difficult to perform large trials [15].

\section{Conclusion}

In summary, in this report we describe and illustrate an interesting case of aggressive hemangioma, with its typical symptomatic presentation and with its main imaging features, as well as its histopathological findings. In addition, we performed a brief review of the literature on imaging findings, clinical picture and evolution in these cases, possible differential diagnoses and therapeutics. Although uncommon, it is important for radiologists and orthopedists to be aware of aggressive hemangioma in order to diagnose patients with symptoms of spinal pain.

\section{Information}

- Study developed in the Radiology Department of the Hospital Geral de Fortaleza (HGF), Fortaleza-CE, Brazil.

- No funding was used in this study.

- There is no conflict of interest of the authors in this work/document.

\section{Conflicts of Interest}

The authors declare no conflicts of interest regarding the publication of this paper.

\section{References}

[1] Chen, H.I., Heuer, G.G., Zaghloul, K., et al. (2007) Case Report. Lumbar Vertebral Hemangioma Presenting with the Acute Onset of Neurological Symptoms. Journal of Neurosurgery, 7, 80-85. https://doi.org/10.3171/SPI-07/07/080

[2] Dagi, T.F. and Schmidek, H.H. (1990) Vascular Tumors of the Spine. In: Sundaresan, N., Schmidek, H.H., Schiller, A.L., et al, Eds., Tumors of the Spine: Diagnosis and Clinical Management. WB Saunders Co., Philadelphia, 181-191.

[3] Acosta Jr, F.L., Sanai, N., Chi, J.H., et al. (2008) Comprehensive Management of Symptomatic and Aggressive Vertebral Hemangiomas. Neurosurgery Clinics of North America, 19, 17-29. https://doi.org/10.1016/j.nec.2007.09.010

[4] Cheung, N.K., Doorenbosch, X. and Christie, J.G. (2011) Rapid Onset Aggressive Vertebral Haemangioma. Childs Nervous System, 27, 469-472. https://doi.org/10.1007/s00381-011-1391-3

[5] Lowe, L.H., Marchant, T.C., Rivard, D.C., et al. (2012) Vascular Malformations: Classification and Terminology the Radiologist Needs to Know. Seminars in Roentgenology, 47, 106-117. https://doi.org/10.1053/j.ro.2011.11.002

[6] Goldstein, C.L., Varga, P.P., Gokaslan, Z.L., et al. (1976) Spinal Hemangiomas: Results of Surgical Management for Local Recurrence and Mortality in a Multicenter Study. Spine, 40, 656-664. https://doi.org/10.1097/BRS.0000000000000840

[7] Pinto, D.S., Hoisala, V.R., Sarkar, P., et al. (2017) Aggressive Vertebral Body Hemangioma Causing Compressive Mielopathy-Two Case Reports. Journal of Orthopaedic Case Reports, 7, 7-10. 
[8] Friedman, D.P. (1996) Symptomatic Vertebral Hemangiomas: MR Findings. American Journal of Roentgenology, 167, 359-364. https://doi.org/10.2214/ajr.167.2.8686604

[9] Cloran, F.J., Pukenas, B.A., Loevner, L.A., et al. (2015) Aggressive Spinal Haemangiomas: Imaging Correlates to Clinical Presentation with Analysis of Treatment Algorithm and Clinical Outcomes. The British Journal of Radiology, 88. https://doi.org/10.1259/bjr.20140771

[10] Schrock, W.B., Wetzel, R.J., Tanner, S.C., et al. (2011) Aggressive Hemangioma of the Thoracic Spine. Journal of Radiology Case Reports, 5, 7-13. https://doi.org/10.3941/jrcr.v5i10.828

[11] Laredo, J.D., Assouline, E., Gelbert, F., et al. (1990) Vertebral Hemangiomas: Fat Content as a Sign of Aggressiveness. Radiology, 177, 467-472.

https://doi.org/10.1148/radiology.177.2.2217787

[12] Byvaltsev, V.A., Stepanov, I.A. and Kichigin, A.I. (2019) The Role of Diffusion-Weighted MRI of Patients with Spine Metastases. Colunal Columna, 18, 289-293. https://doi.org/10.1590/s1808-185120191804225382

[13] Geneidi, E.A.S.H., Ali, H.I. and Dola, E.F. (2016) Role of DWI in Characterization of Bone Tumors. The Egyptian Journal of Radiology and Nuclear Medicine, 47, 919-927. https://doi.org/10.1016/j.ejrnm.2016.06.017

[14] Neubauer, H., Evangelista, L., Hassold, N., et al. (2012) Diffusion-Weighted MRI for Detection and Differentiation of Musculoskeletal Tumorous and Tumor-Like Lesions in Pediatric Patients. World Journal of Pediatrics, 8, 342-349. https://doi.org/10.1007/s12519-012-0379-8

[15] Vasudeva, V.S., Chi, J.H. and Groff, M.W. (2016) Surgical Treatment of Aggressive Vertebral Hemangiomas. Neurosurgical Focus, 41, 1-12. https://doi.org/10.3171/2016.5.FOCUS16169 